\title{
Over-Current Relay Model Implementation for Real Time Simulation \& Hardware-In-the-Loop (HIL) Validation
}

\author{
Muhammad Shoaib Almas, Rujiroj Leelaruji, and Luigi Vanfretti \\ Royal Institute of Technology (KTH) \\ Teknikringen 33, SE-100 44, Stockholm, Sweden \\ Email: msalmas@kth.se, rujiroj@kth.se luigiv@kth.se
}

\begin{abstract}
Digital microprocessor based relays are currently being utilized for safe, reliable and efficient operation of power systems. The overcurrent protection relay is the most extensively used component to safeguard power systems from the detrimental effects of faults. Wrong settings in overcurrent relay parameters can lead to false tripping or even bypassing fault conditions which can lead to a catastrophe. Therefore it is important to validate the settings of power protection equipment and to confirm its performance when subject to different fault conditions. This paper presents the modeling of an overcurrent relay in SimPowerSystems (MATLAB/Simulink). The overcurrent relay has the features of instantaneous, time definite and inverse definite minimum time (IDMT) characteristics. A power system is modeled in SimPowerSystems and this overcurrent relay model is incorporated in the test case. The overall model is then simulated in real-time using Opal-RT's eMEGAsim real-time simulator to analyze the relay's performance when subjected to faults and with different characteristic settings in the relay model. Finally Hardware-in-the-Loop validation of the model is done by using the overcurrent protection feature in Schweitzer Engineering Laboratories Relay SEL-487E. The event reports generated by the SEL relays during Hardware-inthe-Loop testing are compared with the results obtained from the standalone testing and software model to validate the model.
\end{abstract}

\begin{tabular}{ll} 
& \multicolumn{1}{c}{ ACRONYMS } \\
CT & Current Transformer \\
HIL & Hardware-in-the-Loop \\
RT & Real-Time \\
RTS & Real-Time Simulation/Simulators \\
SIL & Software-in-the-Loop \\
SPS & SimPowerSystems \\
VT & Voltage Transformer
\end{tabular}

\section{INTRODUCTION}

A power system is vulnerable to faults, either due to natural disasters or by misoperation of the system due to operators' negligence. This can result in permanent damage to power system components leading to considerable costs for their replacement and in longer disconnections of power supply to customers, which is highly undesirable. This sets a requirement for a power system to sustain faults, while protection systems should minimize the damage in important components and the effect of faults as much as possible. This is achieved by using power system protection techniques and methodologies [1]. Microprocessor-based relays have their own algorithms for monitoring the power system through current and voltage inputs from CTs and VTs respectively. Protection relays are thoroughly tested using relay test sets to confirm their reliability and safe operation before commissioning them in a substation.

With the advent of RTS and compact reconfigurable I/O controllers, large power systems can be simulated and their behavior can be analyzed in both steady state and faulted conditions. Based on this analysis, protection system and power system controllers can be developed for more efficient, reliable and safe operation of power systems. RTS are currently being used for HIL validation, developing algorithms for adaptive protection, designing system integrity protection schemes (SIPS), remedial action schemes (RAS) and other applications [2].

In this paper, a detailed model for overcurrent relays is provided. To assess the performance of this model a test system is designed in SPS and is simulated in RT using OpalRT's eMEGAsim real-time simulator. Once the SIL model is certified, it is further validated by HIL simulation using the overcurrent protection function of Schweitzer Engineering Laboratories (SEL) relay SEL-487E. The results obtained by the SIL and the HIL are compared. SPS does not have a dedicated library for protection functions. Therefore it is necessary to validate the model with HIL so that the validated software model can be used for accurate representation of power system protection components. Similar approach for protection relay model validation has been demonstrated in [3] [4] using different modeling platform and RTS.

The remainder of the paper is arranged as follows. Section II offers a literature review on overcurrent relays. Section III presents the details of the overcurrent relay modelled in SPS. Section IV focuses on the design of test system in SPS and incorporation of proposed relay model in the test case. SIL simulation and results are discussed in Section V, while standalone testing and HIL validation is explained in Section VI. Finally in Section VII, conclusions are drawn and future work is outlined.

\section{OVERCURRENT RELAyS}

As the name states, an overcurrent relay provides protection against over currents. This relay uses current inputs from a CT and compares the measured values with preset values. Figure 1 shows the logical representation of an overcurrent relay. If the input current value exceeds the preset value, the relay detects an overcurrent and issues a trip signal to the breaker which opens its contact to disconnect the protected equipment. When the relay detects a fault, the condition is called fault pickup. The relay can send a trip 


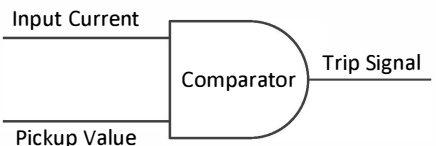

Fig. 1. Logical representation of Over-Current Relay

signal instantaneously after picking up the fault (in the case of instantaneous overcurrent relays) or it can wait for a specific time before issuing a trip signal (in the case of timeovercurrent relays). This time delay is also known as the operation time of the relay, and is computed by the relay on the basis of the protection algorithm incorporated in the microprocessor [5].

\section{A. Classification of Over-Current Relays}

Overcurrent relays are classified on the basis of their operation time, in the following three categories:

1) Instantaneous Overcurrent Relay: These relays instantaneously send a trip command to the breaker as soon as the fault is detected (input current greater than the preset value). They do not have any intentional time delay. They are usually implemented close to the source where the fault current level is very high and a small delay in operation of relay can cause heavy damage to the equipment. So an instantaneous relay is used there to detect and respond to a fault in few cycles.

2) Definite Time Overcurrent Relay: This type of overcurrent relay is used for backup protection (e.g. back up protection for transmission line where primary protection is distance relay). If the distance relay does not detect a line fault and does not trip the breaker, then after a specific time delay, the overcurrent relay will send a trip command to the breaker. In this case, the overcurrent relay is time delayed by a specific time which is just greater than the normal operating time of the distance relay plus the breaker operation time.

3) Inverse Definite Minimum Time (IDMT) Overcurrent Relay: This relay has an inverse time characteristic. This means that the relay operating time is inversely proportional to the fault current. If the fault current is higher, the operating time will be lesser [6]. It can be graded for a very large range of operating times and fault currents [7]. The characteristics of an IDMT overcurrent relay depend on the type of standard selected for the relay operation. These standards can be ANSI, IEEE, IAC or user defined. The relay calculates the operation time by using the characteristic curves and their corresponding parameters [8]. Any of the above mentioned standards can be used to implement a characteristic curve for an overcurrent relay. The overcurrent relay will then calculate the operation time corresponding to that particular characteristic curve.

In accordance with IEC 60255 or BS142, the characteristics of IDMT relays are represented with the following equation:

$$
T=\frac{C}{\left(\frac{I}{I_{s}}\right)^{\alpha}-1} \times T M S
$$

where:

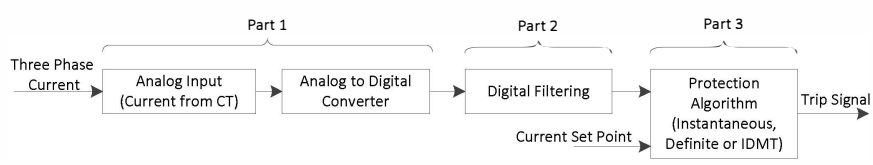

Fig. 2. Functional Block Diagram of an Overcurrent Relay

$T$ : Relay operation time.

$C$ : Constant for relay characteristic.

$I_{s}$ : Current Set point.

I: Current Input to the relay.

$\alpha$ : Constant Representing Inverse Time Type $(\alpha>0)$.

$T M S$ : Time Multiplier setting controls the relay tripping time.

By using appropriate TMS settings, the grading of a protection network system can be achieved [9]. The range of TMS is normally 0.1 to 1.0.Different types of curves can be obtained by varying $\alpha$ and $C$ [10]. Table I below shows values for $\alpha$ and $C$ corresponding to each curve:

TABLE I

DifFERENT Ty PES OF INVERSE ChARACTERISTICS CURVES

\begin{tabular}{|l|c|c|}
\hline Relay Characteristic Type & $\boldsymbol{\alpha}$ & $\mathbf{C}$ \\
\hline Standard Inverse & 0.02 & 0.14 \\
\hline Very Inverse & 1 & 13.5 \\
\hline Extremely Inverse & 2 & 80 \\
\hline Long Inverse & 1 & 120 \\
\hline
\end{tabular}

\section{Overcurrent Relay Modeling For Real-Time SIMULATION}

The detailed model of an overcurrent relay is implemented in the SimPowerSystems (MATLAB/Simulink) Toolbox. The reason for using the SPS Toolbox is because it operates in the Simulink environment and is a dedicated tool for modeling and simulating power systems [11]. Another motivation in using SPS is because it is compatible with the OPAL-RT eMEGAsim real-time simulator [12] which is used to simulate the power system model in RT and for HIL validation of the model.

The block diagram presented in Figure 2 shows the three major functional components of an overcurrent relay. These components and their functionalities are discussed next.

\section{A. Part 1}

In order to present an accurate model of the microprocessor based overcurrent relay, the current inputs which are analog signals are converted to digital signals by Analog to Digital Conversion. In Simulink this can be achieved by using a Zero Order Hold Block. This ZOH block is available in the Discrete Library of Simulink.

\section{B. Part 2}

A digital filter is used to extract the fundamental signal. A down sampler is used in order to reduce the sampling rate. Down sampling helps avoiding anti-aliasing [13] effects. The digital filter used here is a low pass digital FIR filter [14]. 


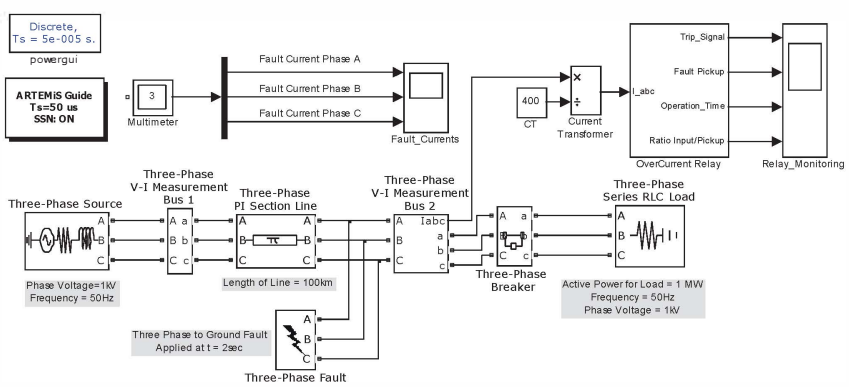

Fig. 5. Test Case Model developed in SimPowerSystems

\section{Part 3}

Once the RMS value of the current is obtained, this current is fed into the relay protection algorithm block. This block compares the current value with the pickup value. If the input current exceeds the pickup value, the relay will compute the operation time for this scenario taking into consideration the characteristic curve (Standard Inverse, Very Inverse, Extremely Inverse or Long Inverse) and sends a trip signal once the operation time is elapsed.

Figure 3 in p. 7 shows the overall Simulink model of the overcurrent relay.

The protection algorithm implemented in the model is shown in Fig. 4, p. 7. The overcurrent model is masked to a single subsystem (block) and a graphical user interface is provided where the user can select the type of overcurrent relay (instantaneous, time definite or IDMT) and can further select the different characteristic curves for IDMT overcurrent relay.

\section{Test Case in SimpowerSystems}

Figure. 5 shows the test case model designed in SPS to couple the overcurrent relay model and investigate its characteristics when subjected to faults. The major components of the test case are:

- Three phase voltage source, $50 \mathrm{~Hz}, 1 \mathrm{kV}$ phase voltage.

- Transmission Line ( $\pi$-section), $100 \mathrm{~km}$

- Three phase fault block to introduce single phase to ground, phase to phase and three phase to ground faults.

- Circuit breaker to disconnect load with trip signals from the overcurrent relay model.

- Three phase series RLC load of $1 \mathrm{MW}$.

- Simulation time step $=50 \mu$ sec.

In order to guarantee a safe, reliable and fast operation of overcurrent relays, settings such as pickup value, time multiplier settings, characteristic curves, and others, have to be chosen carefully. Otherwise, the relay can either not detect the faulted conditions (and will not trip) or send a false tripping command. Figure 6 shows some of the general steps which are followed in selecting the pickup value of the overcurrent relay. Following these steps, fault analysis of the test system was conducted. The results are shown in Fig. 7.

Table II shows the settings of the overcurrent relay model which are based on the results from fault analysis (Fig. 7)

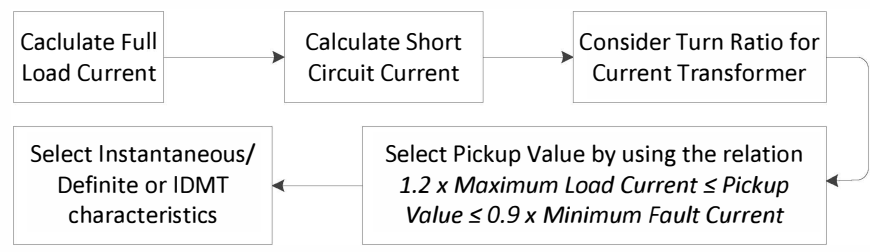

Fig. 6. Steps Involved in Selecting Pickup Values for Overcurrent Relays

TABLE II

TEST SYSTEM ANALYSIS AND RELAY SETTINGS

\begin{tabular}{|c|l|c|}
\hline \multirow{4}{*}{ Measurements } & Full Load Current & $330 \mathrm{~A}$ \\
\cline { 2 - 3 } & $\begin{array}{l}\text { Minimum Fault Current (Single } \\
\text { Phase to Ground) }\end{array}$ & $1760 \mathrm{~A}$ \\
\cline { 2 - 3 } & $\begin{array}{l}\text { Maximum Fault Current (Three } \\
\text { Phase to Ground) }\end{array}$ & $3088 \mathrm{~A}$ \\
\hline \multirow{3}{*}{ Relay Settings } & Current Transformer Ratio & $400: 1$ \\
\cline { 2 - 3 } & Pickup Value & $1 \mathrm{~A}$ \\
\cline { 2 - 3 } & Time Multiplier Setting & 0.5 \\
\hline
\end{tabular}

and the procedure mentioned in Fig 6. TMS was set to 0.5 to see a noticeable difference in operating time of the relay when using different IDMT characteristic curves as shown in Fig 8. From Table II it is obvious that the introduction of three phase to ground fault will result in the CT's secondary current equal to $7.72 \mathrm{~A}$ (i.e. 7.72 times the pickup value).

\section{SOFTWARE-IN-THE-LOOP VALIDATION}

The parameters of the overcurrent relay model were updated and the model was simulated offline. For real-time SIL validation steps presented in Figure 9 were followed. The trip signal generated from the Simulink model was sent to one of the digital output of the simulator. This digital output was looped back through one of the digital inputs. This digital input was configured to control the status of the breaker. So when a fault is introduced and the relays picks up the overcurrent condition, it sends a trip signal (digital signal 0' for normal and 1' for trip) to the digital output of simulator which is coupled with the digital input of the simulator. This digital input opens the breaker in the SPS model in real-time.

In the test case model, the three phase to ground fault was applied at $t=2 \mathrm{sec}$. The results for standard inverse, very inverse and extremely inverse characteristic curves are shown in Fig. 10 to 12. Only a single phase is shown in the results as its a case of symmetrical fault and the other two phases will be phase shifted by 120 degrees. Table III shows the comparison of results from proposed model with the theoretical calculations.

\section{HARDWARE-IN-THE-LOOP VALIDATION}

In order to validate the software model and compare its performance with an actual relay, HIL simulation is carried out. For this purpose a transformer differential protection relay from Schweitzer Engineering Laboratories, SEL-487E [15], is used. To amplify the low level current outputs from realtime simulator, amplifiers from Megger [16] are used. The maximum current which can be sourced from Analog Outputs 

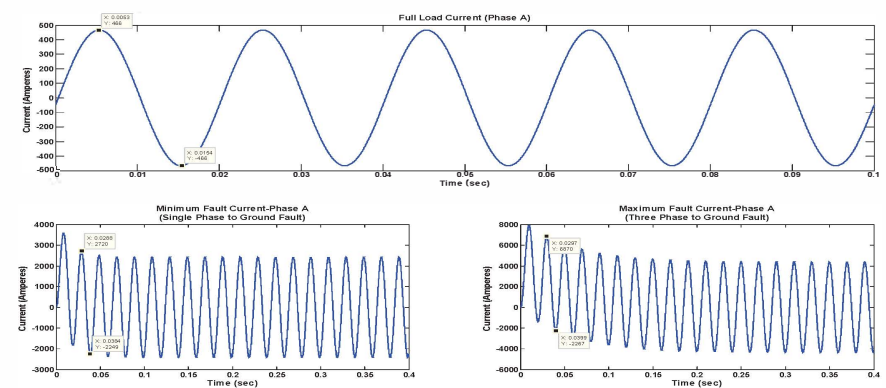

Fig. 7. Fault Analysis of the Test System (only Phase A is shown)

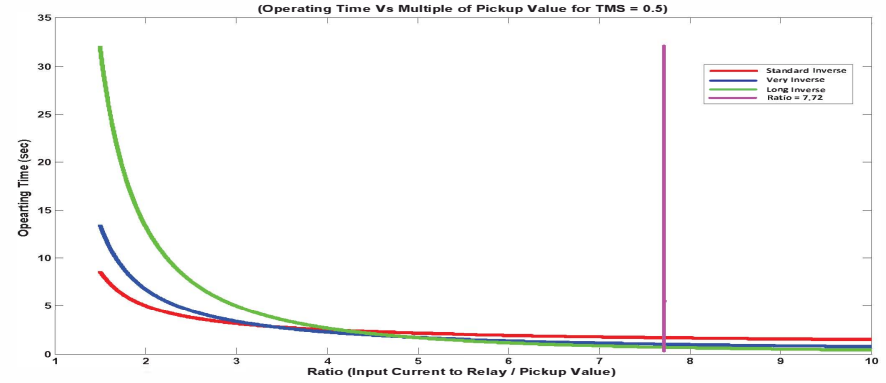

Fig. 8. Different IDMT characteristic curves for TMS $=0.5$. The vertical line at ratio $=7.72$ is the region of interest in the test case

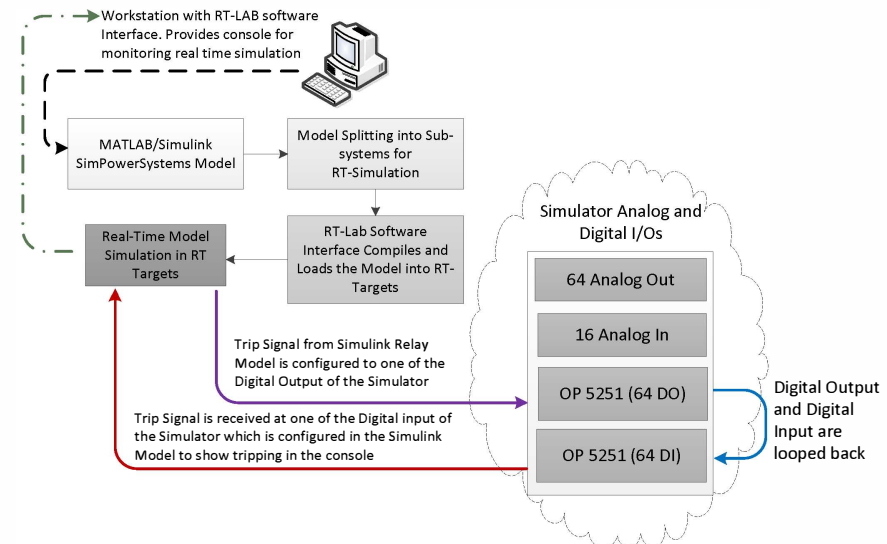

Fig. 9. Steps for Real-Time SIL Validation of the Relay Model
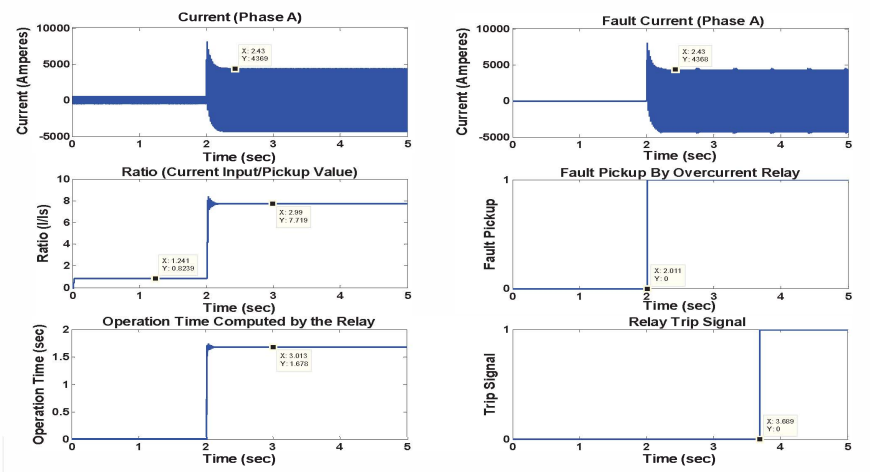

Fig. 10. Results for Relay Model with Standard Inverse Curve

of the simulator is $\pm 20 \mathrm{~mA}$. In order to make sure that the current level never exceeds this limit, the three phase current signals are attenuated by a factor of 1000 . As the maximum fault current for this test case model is $3088 \mathrm{~A}$ (see Table II) and the CT ratio is set to 400:1. So the maximum fault
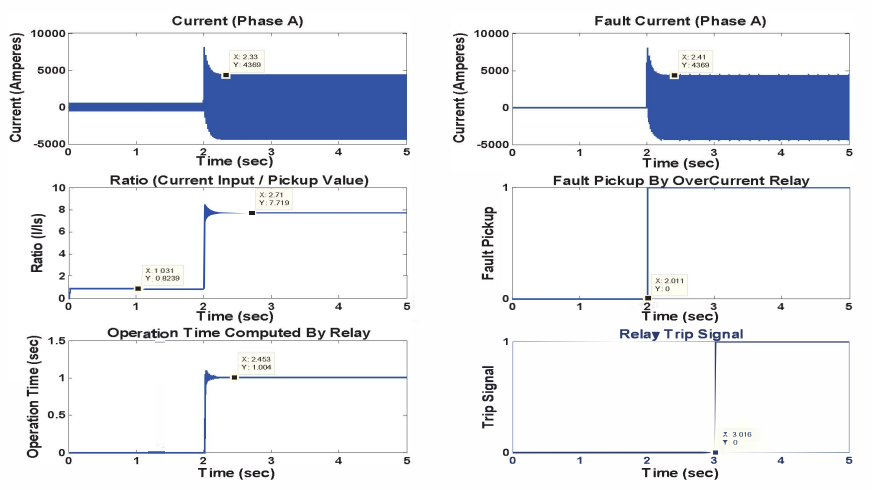

Fig. 11. Results for Relay Model with Very Inverse Curve
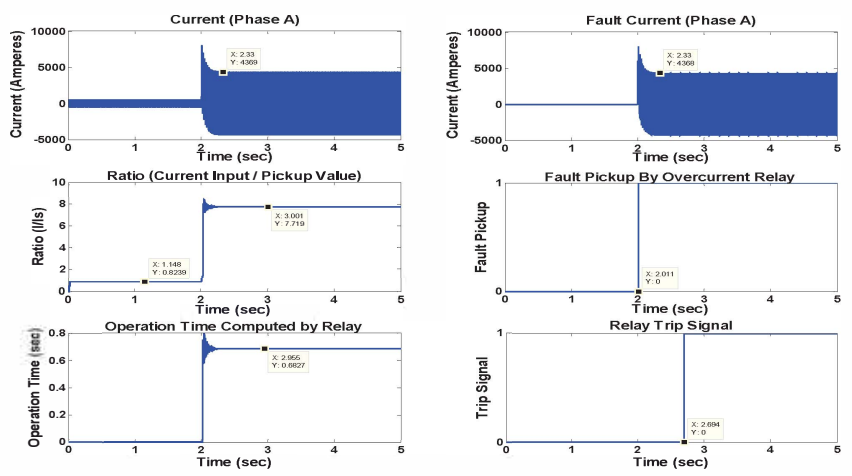

Fig. 12. Results for Relay Model with Extremely Inverse Curve

TABLE III

COMPARISON OF THE RESULTS FROM PROPOSED RELAY MODEL SIL VALIDATION VS IDEAL CALCULATIONS

\begin{tabular}{|c|c|c|c|}
\hline \multicolumn{4}{|c|}{$\begin{array}{c}\text { Summary of Results From Proposed Relay Model } \\
\text { (Fault Applied at } t=2 \mathrm{sec})\end{array}$} \\
\hline $\begin{array}{ll}\text { Time (sec) } & \text { Curve } \\
\end{array}$ & $\begin{array}{l}\text { Standard } \\
\text { Inverse }\end{array}$ & $\begin{array}{l}\text { Very } \\
\text { Inverse }\end{array}$ & $\begin{array}{l}\text { Extremely } \\
\text { Inverse }\end{array}$ \\
\hline Operating Time & 1.6780 & 1.0045 & 0.6827 \\
\hline Ideal Operating Time & 1.6777 & 1.0040 & 0.6826 \\
\hline Trip Signal Time & 3.6890 & 3.0160 & 2.6940 \\
\hline Ideal Trip Signal Time & 3.6780 & 3.0040 & 2.6826 \\
\hline
\end{tabular}

The ideal results are calculated using Eq. (1). Trip Signal Time $=$ Time at which fault is applied + Operating Time.

current which can be seen by the relay is $7.72 \mathrm{~A}$. With the attenuation of this signal by a factor of 1000 , the current from the Analog Outputs of the Simulator will be $\pm 7.72 \mathrm{~mA}$ which is well within the range of the current output capacity of the simulator. In order to compensate for this attenuation, the analog outputs of the simulator are fed to SMRT-1 amplifiers (Megger) which amplify the signal by the factor of 1000 . This amplified signal is then fed to the CT inputs of the SEL-487E relay. In the software test model in Section IV, few modifications were made i.e. including vendor specific blocks from RT-Lab [17] library to access the Analog Outputs of the Simulator, as shown in Fig. 13.

In addition, one digital inputs of the simulator are coupled with the digital outputs of SEL-487E, which is configured to change its contacts in case of a trip. The digital inputs of the 


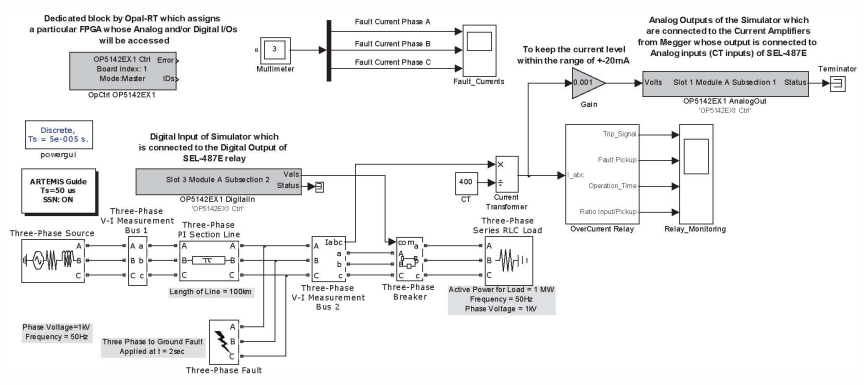

Fig. 13. Test case model with modifications for HIL simulation

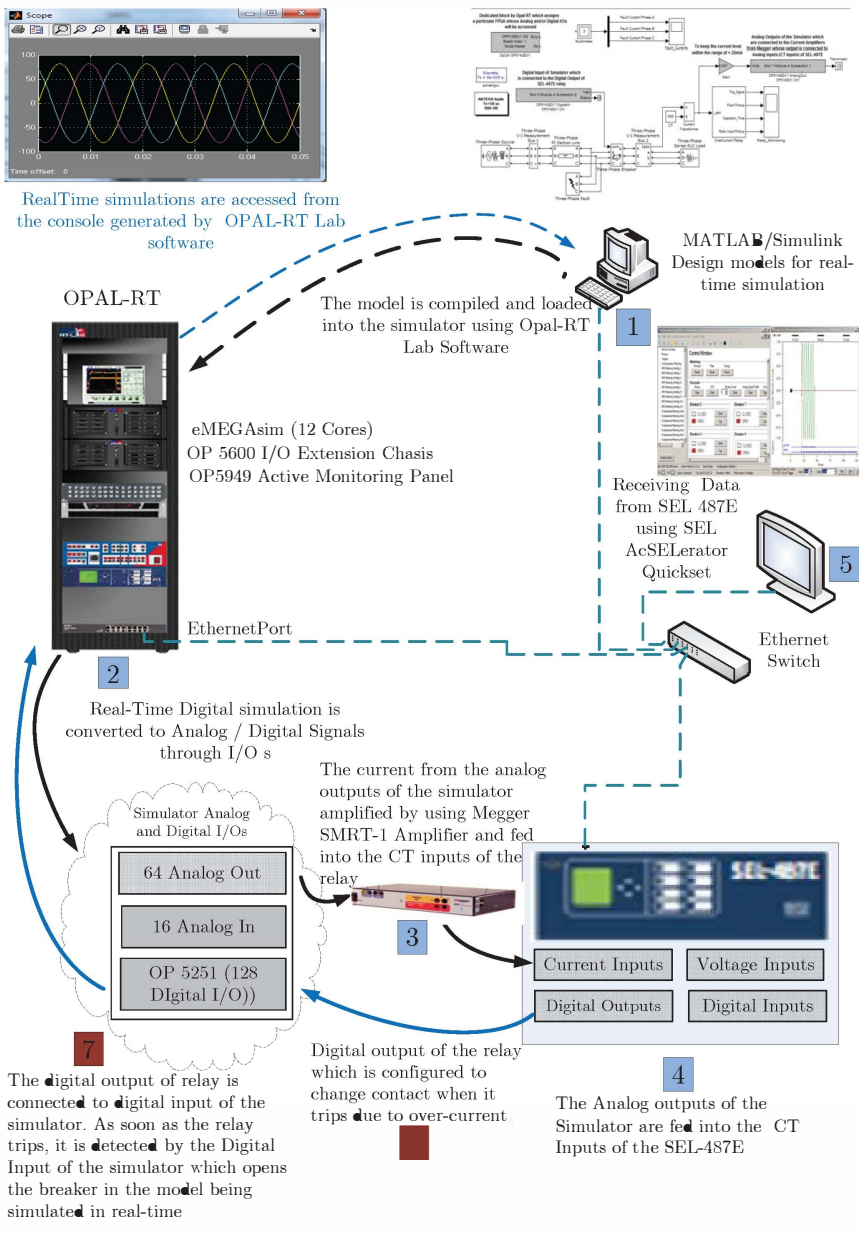

Fig. 14. Model-to-Data Work-Flow for HIL simulation. Solid Lines indicate hardwired connections, dashed lines indicate digital data streams over ethernet

simulator are configured to change the breaker status in the SPS model in real-time. Figure 13 shows the test case model with additional blocks which are highlighted. The overall workflow from building the model to simulating it in realtime and executing HIL validation is shown in Fig. 14.

In order to enable the overcurrent feature of the SEL-487E, SEL AcSELerator Quickset [18] is used. The characteristic curve chosen for the validation is extremely inverse curve. The same settings were incorporated in SEL-487E (Figure 15) as in the software model (see Table II). A fault is introduced at $t=2 \mathrm{sec}$. The ACSELERATOR Analytic Assistant [19] is used

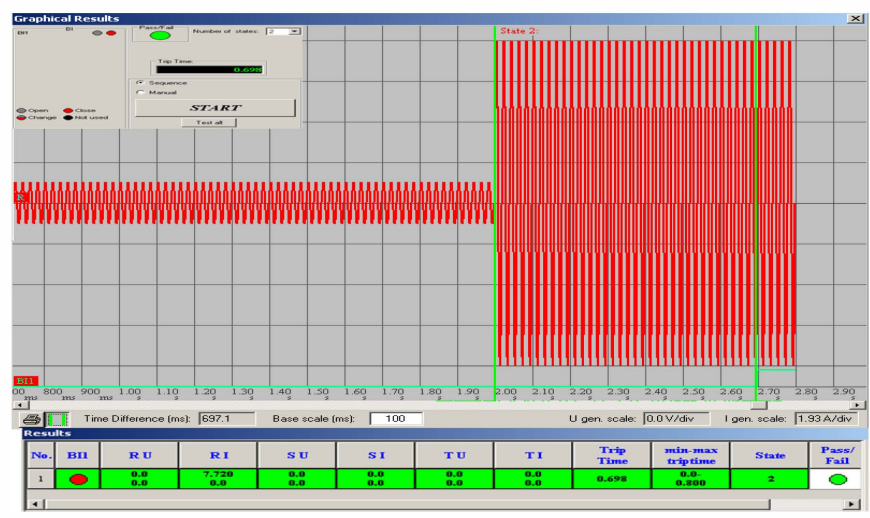

Fig. 16. Results from Standalone test using Freja-300. Showing the tripping time of $0.698 \mathrm{sec}$ with TMS $=0.5$, pickup value $=1$ and characteristic curve of extremely inverse. Scale is $1.93 \mathrm{~A} / \mathrm{div}$

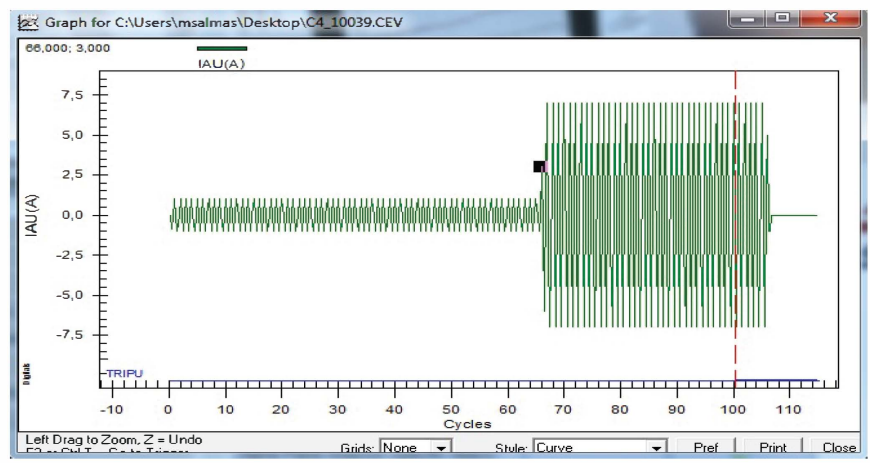

Fig. 17. Results from SEL-487E event report generated by HIL simulation. The operating time calculated here is 34.5 cycles which corresponds to 0.69 sec

to display event report data as oscillography. In addition Freja 300 (Relay Test System) [20] is used to inject the secondary currents to SEL-487E to confirm the tripping times obtained from HIL simulation. For standalone testing, the software interface for Freja 300 i.e. Freja Win [21] is used to give secondary injections of $0.98 \mathrm{~A}$ for the first 2 seconds and then a step increase in current to $7.72 \mathrm{~A}$. The results are presented in Fig. 16 showing that before the fault is applied, the current input is equal to $0.98 \mathrm{~A}$ which is lesser than the pickup value of $1 \mathrm{~A}$. As the fault is applied at $t=2 \mathrm{sec}$, the current rises up to $7.72 \mathrm{~A}$. At this point the relay picks up the fault and its IDMT characteristic is activated which finally generates a trip signal after $0.698 \mathrm{sec}$. As the fault is applied at $t=2$ sec., and operating time of relay is $0.698 \mathrm{sec}$., so the tripping time is equal to $2.698 \mathrm{sec}$. At $t=2.698 \mathrm{sec}$, the relay $\mathrm{D} / \mathrm{O}$ changes its contacts and thus it opens the breaker in the SPS model and the load is protected against overcurrent. Figure. 17 shows the oscillography from the event report of SEL-487E resulted from HIL simulation. As soon as the relay trips, SEL-487E generates an event report which can be viewed by using ACSELERATOR Analytic Assistant. Figure. 18 shows the operating time for SIL and HIL validations for different characteristic curves. 


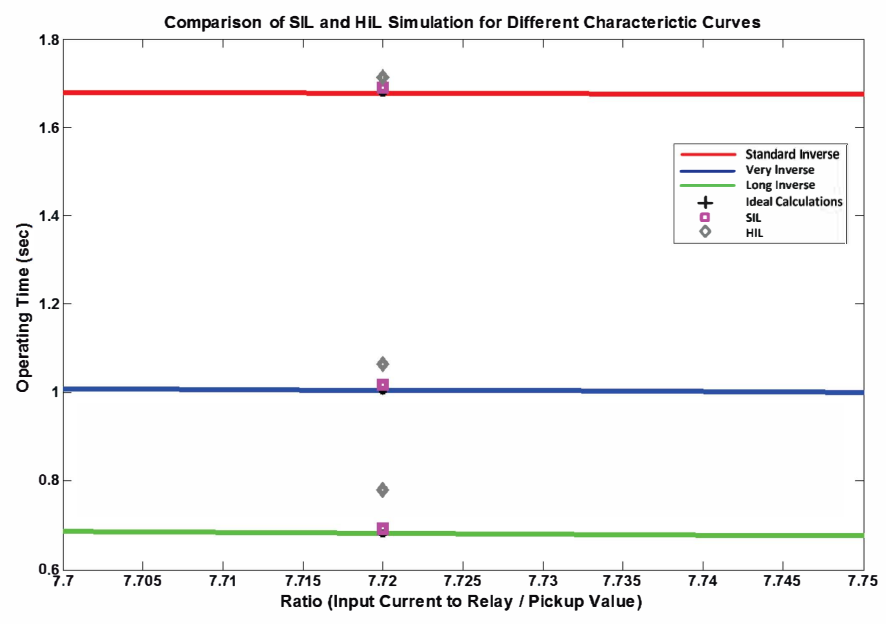

Fig. 18. Comparison of Operating Time by SIL and HIL validations

TABLE IV

COMPARISON OF THE RESULTS FROM PROPOSED RELAY MODEL AND HIL

\begin{tabular}{|l|l|c|c|c|}
\hline \multicolumn{5}{|c|}{$\begin{array}{c}\text { Comparison of Results from Proposed Model and HIL } \\
\text { (Fault Applied at } \boldsymbol{t}=\mathbf{2 s e c} \text { ) }\end{array}$} \\
\hline Curve & Time $($ sec) & Ideal Caculations & SIL & HIL \\
\hline \multirow{2}{*}{ Standard Inverse } & Operating & 1.6777 & 1.6780 & 1.6850 \\
\cline { 2 - 5 } & Trip & 3.6780 & 3.6890 & 3.7135 \\
\hline \multirow{2}{*}{ Very Inverse } & Operating & 1.0040 & 1.0045 & 1.0150 \\
\cline { 2 - 5 } & Trip & 3.0040 & 3.0160 & 3.0650 \\
\hline \multirow{2}{*}{ Extremely Inverse } & Operating & 0.6826 & 0.6827 & 0.6980 \\
\cline { 2 - 5 } & Trip & 2.6826 & 2.6940 & 2.7800 \\
\hline
\end{tabular}

\section{CONCLUSION AND FURTHER WORK}

By utilizing Opal-RT's eMEGAsim real-time simulator, HIL testing of the proposed model is done. The results for both proposed model and HIL are shown in Table IV. Both the proposed software model and HIL gives almost the same result. The difference between Proposed Model and theoretical calculations is about $11 \mathrm{~ms}$. This difference is due to the changing of states of the digital $\mathrm{I} / \mathrm{O}$ of the simulator and the arc extinction process of the three phase circuit breaker used in SPS model [22] which waits for the first zero crossing of the fault current to open the breaker once its external controller changes from 0 ' to 1'. In case of HIL validation, there is some extra delay due to the response of the amplifiers and status changing of digital output contact of SEL-487E. Opal-RT's simulator has the provision to stream out GOOSE (61850-8-1) and Sampled Values (61850-9-2). The proposed model can be used to validate the Station Bus [23] and Process Bus [24] implementation with HIL, this will be reported in a future publication.

\section{ACKNOWLEDGMENT}

M.S. Almas is supported by the STRON $g^{2}$ rid project, funded by Nordic Energy Research.

R. Leelaruji is supported by EKC ${ }^{2}$ - The Swedish Centre of Excellence in Electric Power Engineering.

L. Vanfretti is supported in part by the STRONg ${ }^{2}$ rid project, funded by Nordic Energy Research, by the STandUP for Energy collaboration initiative and the KTH School of Electrical Engineering.

The generosity of Schweitzer Engineering Laboratories, Pullman, WA, USA; for their donation of protection relays, and Megger/Programma, Täby, Sweden; for their donation of different hardware and technical support is deeply acknowledged.

\section{REFERENCES}

[1] J. L. Blackburn and T. J. Domin, Protective Relaying - Principles and Applications, Third Edition. CRC Press, 2006.

[2] Terzija, V. and Valverde, G. and Deyu Cai and Regulski, P. and Madani, V. and Fitch, J. and Skok, S. and Begovic, M.M. and Phadke, A., "WideArea Monitoring, Protection, and Control of Future Electric Power Networks," Proceedings of the IEEE, vol. 99, no. 1, pp. $80-93$, jan. 2011.

[3] Palla, S. ; Srivastava, A.K. ; Schulz, N.N. , "Hardware in the Loop Test for Relay Model Validation.” Arlington, Virginia, USA: Electric Ship Technologies Symposium, 2007. ESTS '07. IEEE, May 2007.

[4] Saran, A. ; Kankanala, P. ; Srivastava, A.K. ; Schulz, N.N. , "Designing and Testing Protective Overcurrent Relay using Real Time Digital Simulation." Edinburgh, Scotland: Grand Challenges in Modeling and Simulation, Summer Simulation Conference, June 2008.

[5] General Electric, "Instruction Manual for Overcurrent Protection (MIFII)," available on-line: http://www.gedigitalenergy.com/multilin/.

[6] IEEE Tutorial Course, "Microprocessor Relays and Protection Systems," Course Text 88EH0269-1PWR, IEEE Service Center, Piscataway, NJ, 1988.

[7] J.P. Whiting, and D. Lidgate, "Computer Prediction of IDMT Relay Settings and Performance for Interconnected Power Systems," vol. 130. IEEE Proceedings for Generation, Transmission and Distribution, May 1983.

[8] Walter A. Elmore, "Protective Relaying Theory and Applications," ABB Power T\&D Company Inc., Tech. Rep., 1994.

[9] Schneider Electric, "Protective Relay Settings- Understanding the IEC based IDMT Settings of Phase Overcurrent Protection," ABB Power T\&D Company Inc., Tech. Rep., 1994, available on-line: http://selink.schneider-electric.com.sg/selink.

[10] Benmouyal, G. ; Meisinger, M ; Burnworth, J. et al., "IEEE Standard Inverse-Time Characteristic Equations for Overcurrent Relays," IEEE Transactions on Power Delivery, vol. 14, no. 3, pp. 868 - 872, July, 1999.

[11] The MathWorks, "SimPowerSystems User's Guide," available on-line: http://www.mathworks.com/help.

[12] Opal-RT, "eMEGAsim PowerGrid Real-Time Digital Hardware in the Loop Simulator," available on-line: http://www.opal-rt.com/.

[13] Edmund. O. Schweitzer III, and Daqing Hou, "Filtering For Protective Relays," vol. 130. Atlanta, Georgia: 47th Annual Georgia Tech Protective Relay Conference, April 1993.

[14] Zocholl, S.E., "Integrated Metering and Protective Relay Systems," IEEE Transactions on Industry Applications, vol. 25, no. 5, pp. 889 - 893, Sep-Oct, 1989.

[15] SEL, "Protection Relays by Schweitzer Engineering Laboratories," available on-line: http://www.selinc.com/protection/.

[16] "Current and Voltage Amplifiers by Megger," available on-line: http://www.megger.com/cae/story/Index.php?ID=527.

[17] Opal-RT, "RT-LAB Real Time Simulation Software," available on-line: http://www.opal-rt.com/product/rt-lab-professional.

[18] SEL, "SEL AcSELerator Quickset - Tool for modifying SEL Relays Settings," available on-line: http://www.selinc.com/SEL-5030/.

[19] —_, "SEL AcSELerator Analytic Assistant SEL-5601 Event Analysis Software," available on-line: http://www.selinc.com/SEL-5601/.

[20] Megger, "Freja 300 - Relay Test System," available on-line: http://tinyurl.com/Freja300.

[21] — , "Freja Win - Graphical Interface for Freja-300 Relay Test System," available on-line: http://tinyurl.com/FrejaWin.

[22] The MathWorks, "Three Phase Circuit Breaker Block Avaliable in SimPowerSystems Library," available on-line: http://tinyurl.com/3ph-brkr-sps.

[23] IEC Standard, "Communication networks and systems in substations - Part 8-1: Specific Communication Service Mapping (SCSM) - Mappings to MMS (ISO 9506-1 and ISO 9506-2) and to ISO/IEC 8802-3.'

[24] _ - "Communication networks and systems in substations - Part 9-2: Specific Communication Service Mapping (SCSM) - Sampled values over ISO/IEC 8802-3." 


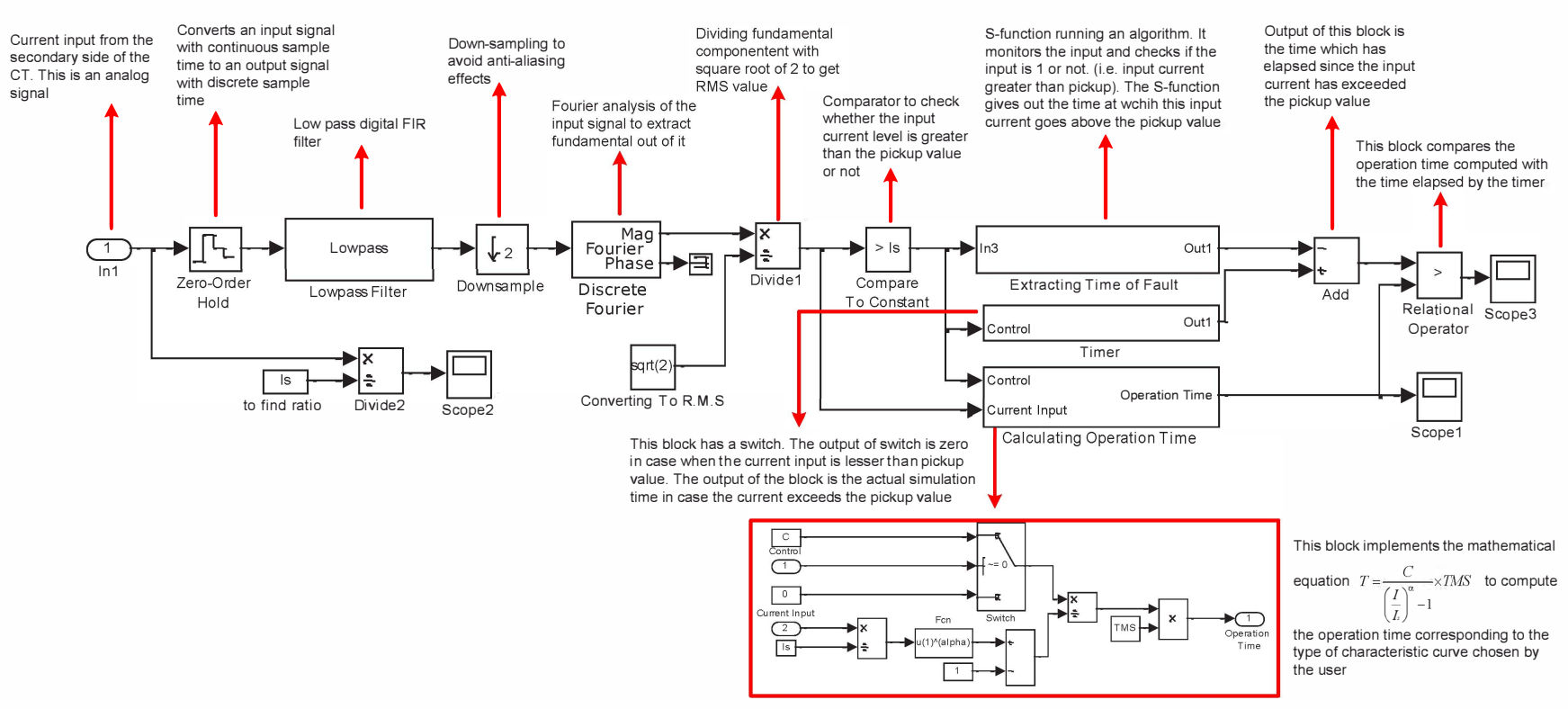

Fig. 3. Detailed Model of Overcurrent Relay Implemented in MATLAB/Simulink

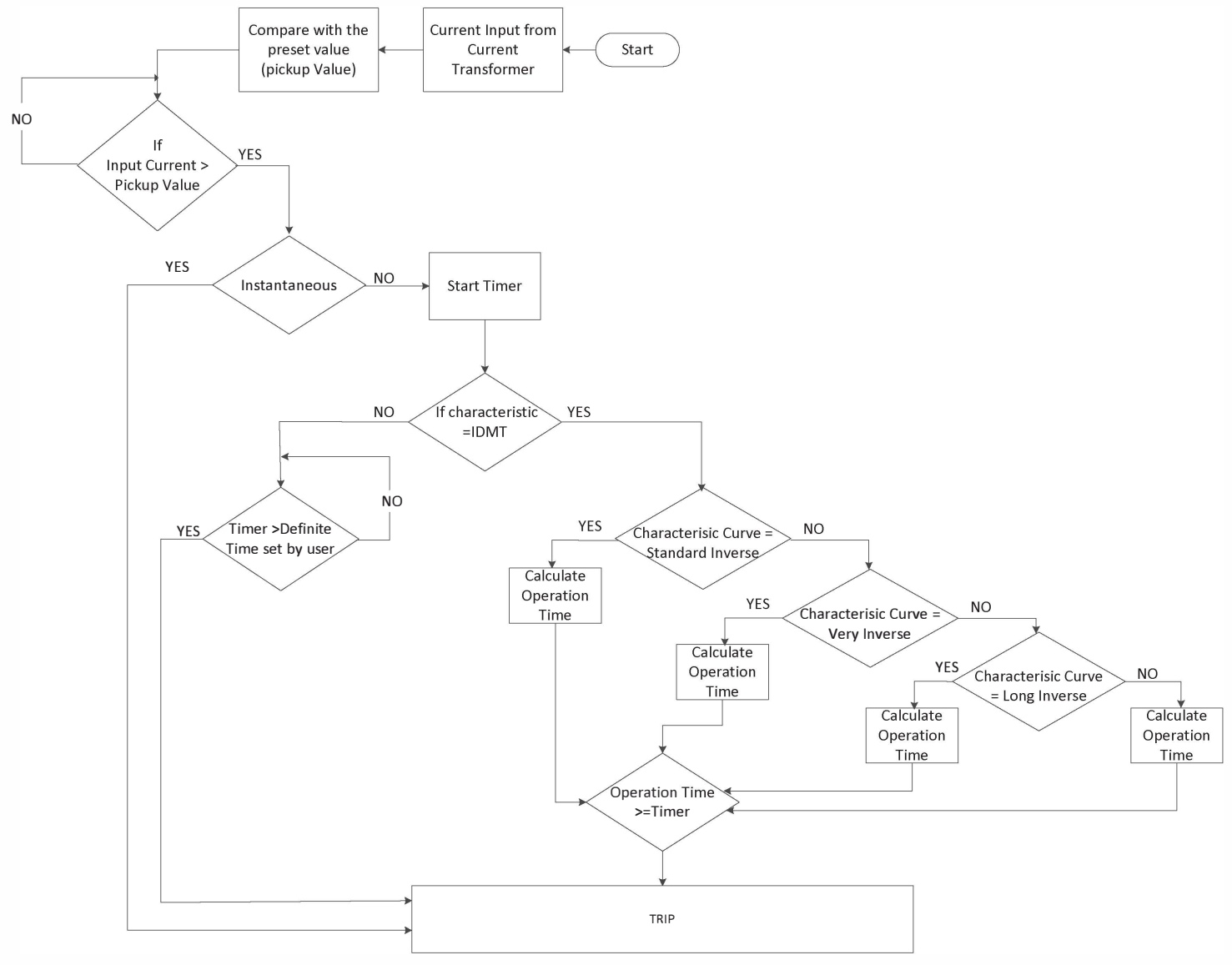

Fig. 4. Protection Algorithm Implemented in the Overcurrent Relay Model 


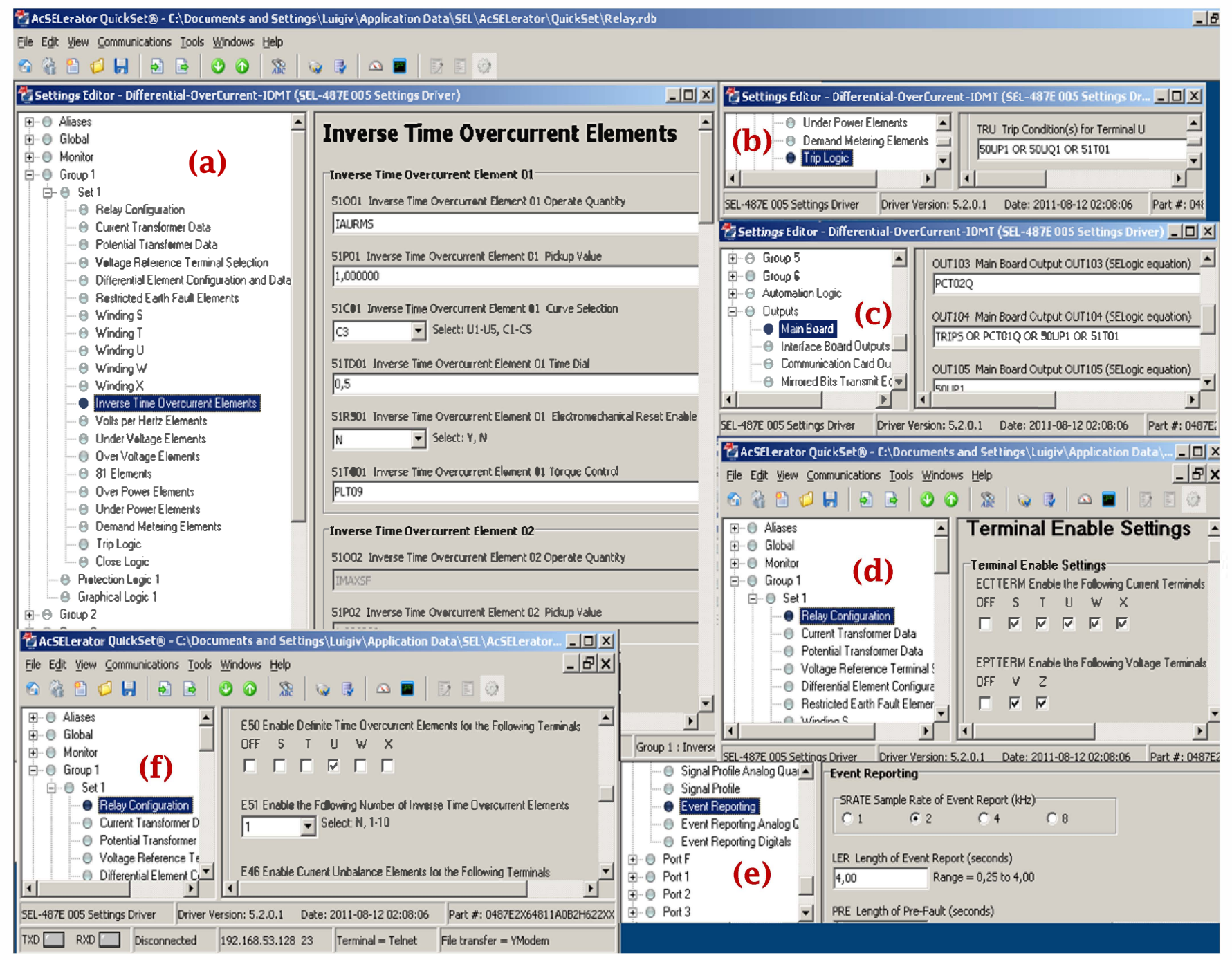

Fig. 15. Settings of SEL-487E relay using AcSELerator Quickset. (a) Inverse time overcurrent element enabling with extremely inverse curve, Pickup value of 1 and TMS of 0.5, (b) Trip logic for the IDMT configuration, (c) Configuring D/O of relay to change its contacts for IDMT trip (d) Enabling CT of relay, (e) Enabling Event Recording, (f) Enabling IDMT feature for Terminal U input of SEL-487 